Boise State University

ScholarWorks

8-24-2018

\title{
Structural Evolution of Molybdenum Disulfide Prepared by Atomic Layer Deposition for Realization of Large Scale Films in Microelectronic Applications
}

\author{
Steven Letourneau \\ Boise State University \\ Elton Graugnard \\ Boise State University
}

\begin{abstract}
Publication Information
Letourneau, Steven; Young, Matthias J.; Bedford, Nicholas M.; Ren, Yang; Yanguas-Gil, Angel; Mane, Anil U.; . . . and Graugnard, Elton. (2021). "Structural Evolution of Molybdenum Disulfide Prepared by Atomic Layer Deposition for Realization of Large Scale Films in Microelectronic Applications". ACS Applied Nano Materials, 1(8), 4028-4037. https://doi.org/10.1021/acsanm.8b00798
\end{abstract}

This is an author-produced, peer-reviewed version of this article. The final, definitive version of this document can be found online at ACS Applied Nano Materials, published by American Chemical Society, as required by the U.S. Department of Energy. Copyright restrictions may apply. https://doi.org/10.1021/acsanm.8b00798. The content of this document may vary from the final published version. 


\title{
Structural evolution of molybdenum disulfide prepared by atomic layer deposition for realization of large scale films in micro-electronic applications
}

\author{
Steven Letourneau, ${ }^{1}$ \\ Matthias J. Young, ${ }^{2}$ \\ Nicholas M. Bedford,3,4 \\ Yang Ren, ${ }^{2}$ \\ Angel Yanguas-Gil, ${ }^{2}$ \\ Anil U. Mane, ${ }^{2}$ \\ Jeffery W. Elam, ${ }^{2}$ \\ Elton Graugnard ${ }^{*}, 1$
}

${ }^{1}$ Micron School of Materials Science and Engineering, Boise State University, 1910 University Dr., Boise, ID 83725

${ }^{2}$ Energy Systems Division, Argonne National Laboratory, 9700 S. Cass Ave., Argonne, Illinois 60439

3 School of Chemical Engineering, University of New South Wales, Sydney, NSW, 2052

4 Materials and Manufacturing Directorate, Air Force Research Laboratory, Wright

Patterson AFB, OH, 45433

Keywords: molybdenum disulfide; $\mathrm{MoS}_{2}$; atomic layer deposition; ALD; X-ray absorption spectroscopy; XAS; high energy X-ray diffraction; XAS; fullrmc; reverse Monte Carlo;

*Email of corresponding author: eltongraugnard@boisestate.edu 


\section{Abstract}

Molybdenum disulfide $\left(\mathrm{MoS}_{2}\right)$ films are attractive materials for electronic and optoelectronic devices, but the temperatures used in the chemical vapor deposition (CVD) of these materials are too high for device integration. Recently, a low temperature atomic layer deposition (ALD) process was demonstrated for growth of $\mathrm{MoS}_{2}$ films at $200{ }^{\circ} \mathrm{C}$ using $\mathrm{MoF}_{6}$ and $\mathrm{H}_{2} \mathrm{~S}$. However, the as-deposited films were amorphous and required annealing to obtain the desired layered structure. The $\mathrm{MoS}_{2}$ films were sulfur-deficient; however, after annealing the crystallinity improved. To study the structure of these films and the process by which they crystallize, we performed X-ray absorption spectroscopy and high-energy X-ray scattering experiments on both as-deposited and annealed $\mathrm{MoS}_{2}$ films. Analysis indicated that molybdenum atoms in the asdeposited films were well coordinated with sulfur, but not well coordinated with other molybdenum atoms when compared to a crystalline reference. Further analysis revealed clusters of the sulfur rich phase $\left[\mathrm{Mo}_{3} \mathrm{~S}\left(\mathrm{~S}_{6}\right)_{2}\right]^{2-}$, which decomposed after annealing in $\mathrm{H}_{2}$ and $\mathrm{H}_{2} \mathrm{~S}$ at $400{ }^{\circ} \mathrm{C}$ and $600{ }^{\circ} \mathrm{C}$. When compared to the sulfur deficient films reported previously for this ALD process, the sulfur rich phase found here indicates that nucleation on the substrate plays an important role in the resulting film stoichiometry, which could be tuned to produce higher quality films for micro-electronic applications. 
This is an author-produced, peer-reviewed version of this article. The final, definitive version of this document can be found online at $A C S$ Applied Nano Materials, published by American Chemical Society. Copyright restrictions may apply. https://doi.org/10.1021/acsanm.8b00798. The content of this document may vary from the final published version.

\section{INTRODUCTION}

Transition metal dichalcogenides (TDMCs) are of significant interest for use in semiconductor devices and energy storage because of their unique properties. ${ }^{1}$ In particular, molybdenum disulfide $\left(\mathrm{MoS}_{2}\right)$ is an attractive candidate to replace silicon in field effect transistors (FETs) because it exhibits a $1.8 \mathrm{eV}$ direct band gap when isolated as a 2D monolayer. ${ }^{2-4}$ High quality $\mathrm{MoS}_{2}$ can be obtained through mechanical exfoliation of natural crystals or chemical vapor deposition (CVD) at high temperatures. Atomic layer deposition (ALD) is a variation of CVD where the precursors are introduced above the substrate sequentially, and films can often be grown at lower temperatures than CVD.5,6 The hallmark of ALD is self-limiting surface chemistries allowing for the coating of high aspect ratio structures with sub angstrom thickness control. ${ }^{6-9}$ Early reports of ALD of $\mathrm{MoS}_{2}$ using various Mo and $\mathrm{S}$ precursors found that as-deposited $\mathrm{MoS}_{2}$ films were amorphous, but annealing the films in an oxygen-free atmosphere at $800{ }^{\circ} \mathrm{C}$ produced layered films. ${ }^{10-14}$ Additionally, these reports found that when the ALD cycle number was low, the films did not exhibit the characteristic Raman spectra of bulk $\mathrm{MoS}_{2} \cdot{ }^{15}$ Interestingly, after many ALD cycles weak Raman peaks appeared, suggesting that a layered structure had formed in low concentrations or microcrystalline regions.

In this work, we aim to understand the local structure and degree of long-range coherence of the amorphous ALD $\mathrm{MoS}_{2}$ films in an effort to identify growth conditions to achieve ultrathin, crystalline $\mathrm{MoS}_{2}$ directly by ALD at low temperatures. While electron microscopy has been used previously to study the structure of ALD $\mathrm{MoS}_{2}$, only a small fraction of the sample volume is probed using this method. ${ }^{16}$ Bulk characterization techniques have also been applied to asdeposited ALD $\mathrm{MoS}_{2}$ films including X-ray photoelectron spectroscopy (XPS), benchtop X-ray diffraction/scattering, and Raman spectroscopy. ${ }^{15}$ These techniques can give insight into the layered structure, but provide limited structural information. Here, we use a combination of synchrotron-based X-ray absorption spectroscopy (XAS) and high-energy X-ray diffraction (HE- 
This is an author-produced, peer-reviewed version of this article. The final, definitive version of this document can be found online at $A C S$ Applied Nano Materials, published by American Chemical Society. Copyright restrictions may apply. https://doi.org/10.1021/acsanm.8b00798. The content of this document may vary from the final published version.

XRD) coupled with atomic pair distribution function (PDF) analysis with reverse Monte Carlo (RMC) modeling to understand the short-range and long-range order in as-deposited and annealed $\mathrm{MoS}_{2}$ films.

XAS is a powerful tool for understanding local chemical environments and is used here to probe the oxidation state and coordination environment of Mo in $\mathrm{ALD} \mathrm{MoS}_{2}$ films. However, structural information from XAS is limited to the first coordination sphere of the probed element. We complement XAS with HE-XRD measurements, coupled with PDF analysis to provide longerrange structural information. ${ }^{17} \mathrm{PDF}$ analysis considers both the diffuse and Bragg components to provide detailed structural information even in the absence of long-range structural coherence. ${ }^{18,19}$ PDF is especially useful for studying the atomic structure of amorphous and nanoscale materials, which inherently lack long-range order. Here, analysis of the X-ray absorption fine structure (XAFS) data helped determine the coordination around Mo-S and MoMo pair peaks, while PDF measurements and RMC modeling provided key insights into the bond pairs of all atoms. In addition to examining the as-deposited films, $\operatorname{ALD} \mathrm{MoS}_{2}$ films were examined following annealing in reducing $\left(\mathrm{H}_{2}\right)$ and sulfurizing $\left(\mathrm{H}_{2} \mathrm{~S}\right)$ environments to understand the impact of these treatments on the $\mathrm{MoS}_{2}$ structural evolution. 


\section{EXPERIMENT}

\subsection{ATOMic Layer Deposition}

$\mathrm{MoS}_{2}$ films were grown by ALD in a custom viscous flow tube reactor as reported previously. ${ }^{20}$ Molybdenum hexafluoride $\left(\mathrm{MoF}_{6}\right.$, Advanced Research Chemicals Inc.) and hydrogen sulfide $\left(\mathrm{H}_{2} \mathrm{~S}, 99.5 \%\right.$, Sigma Aldrich) were used to grow $\mathrm{MoS}_{2}$. The delivery pressures for both precursors were controlled by regulators and $100 \mu \mathrm{m}$ orifices. In our reactor configuration, the partial pressure for the $\mathrm{MoF}_{6}$ was 60 mTorr, while the $\mathrm{H}_{2} \mathrm{~S}$ pressure was 400 mTorr. Both chemicals are extremely hazardous and great care must be taken when working with them. Vented gas cabinets, contained pump exhaust, and cross purge assemblies must be used to ensure safety. To deposit films by ALD, $\mathrm{MoF}_{6}$ was pulsed for $20 \mathrm{~s}$ and purged for $90 \mathrm{~s}$ and $\mathrm{H}_{2} \mathrm{~S}$ was pulsed for $20 \mathrm{~s}$ and purged for $90 \mathrm{~s}$. For the XAS experiments, aluminum oxide powder $\left(\mathrm{Al}_{2} \mathrm{O}_{3}\right.$, Sigma Aldrich) was coated using 200 cycles to ensure a bulk film was grown. Following this deposition, portions of this powder were loaded on a hot stage, evacuated for $>30$ minutes, and then heated to $400{ }^{\circ} \mathrm{C}$ and $600{ }^{\circ} \mathrm{C}$ in a $\mathrm{H}_{2}$ environment for 30 minutes. During annealing the $\mathrm{H}_{2}$ partial pressure was approximately 2 Torr.

For the HE-XRD measurements, OH-terminated carbon nanotubes (CNT-OH, Nanostructured \& Amorphous Materials, Inc.) were coated with 50 cycles of $\mathrm{MoF}_{6}$ and $\mathrm{H}_{2} \mathrm{~S}$ using the same pulsing scheme as described above. Again, portions of the powder were annealed at $400{ }^{\circ} \mathrm{C}$ and $600{ }^{\circ} \mathrm{C}$ separately on a hot stage in both $\mathrm{H}_{2}$ and $\mathrm{H}_{2} \mathrm{~S}$ environments. A 2 Torr $\mathrm{H}_{2}$ partial pressure was again used, while the $\mathrm{H}_{2} \mathrm{~S}$ was kept at 1 Torr. CNT-OH samples were used for XRD measurements to reduce the background signal introduced by the substrate and thereby limit subtraction artefacts during analysis. 


\subsection{CHARACTERIZATION}

X-ray photoelectron spectroscopy (XPS) was performed on a Thermo Fischer k-Alpha+. The XPS data were analyzed using Thermo Avantage software, and all spectra were referenced to the C1s peak $(284.8 \mathrm{eV})$. Fitting of the $2 \mathrm{p}$ and $3 \mathrm{~d}$ peaks was constrained according to the spin-orbit split doublet peak areas and full-width half-maximum (FWHM) according to the relevant core level using a 30\% mixed Gaussian-Lorentzian peak shape. Raman spectroscopy was performed at room temperature on a Renishaw inVia confocal microscope system calibrated to a Si standard using 20x objective and a $10 \%$ neutral density filter with a $633 \mathrm{~nm}$ laser. Powder samples were imaged in a field emission JEOL 2100 transmission electron microscope (TEM) at $200 \mathrm{keV}$. Small amounts of the powder were dropped onto carbon support grids after being dispersed in approximately $2 \mathrm{~mL}$ of methanol and sonicated for 20 - 30 seconds to help break up any agglomeration.

XAS experiments were carried out at the Advanced Photon Source (APS) at Argonne National Laboratory on beamline 10-BM. ${ }^{21}$ Molybdenum foil was referenced, and a $\mathrm{MoS}_{2}$ bulk powder $(<2$ $\mu \mathrm{m}, 99 \%$, Sigma Aldrich) was also used to help determine the amplitude reduction factor, $S^{2}$, parameter. ${ }^{22}$ Powder was applied to Kapton tape and placed in the beam path. XAFS fitting was performed using the Demeter suite to view (Athena) and fit structural models (Artemis and Feff). ${ }^{23}$ HE-XRD measurements were carried out at the APS using beamline 11-ID-C with a PerkinElmer area detector and beam energy of $105.7 \mathrm{keV}$. PDF analysis was performed using GSAS-II. ${ }^{24}$ Calibrations on beam center, sample-to-detector distance and detector tilting were performed with a NIST standard: $\mathrm{CeO}_{2}$, SRM674b. Full integration of the images was performed from 0.7 to $32 \mathrm{Q}\left(\AA^{-1}\right.$, where $\left.\mathrm{Q}=4 \pi \sin (\theta) / \lambda\right)$. The data from blank CNT-OH samples were subtracted to remove any container and substrate effects. FullRMC, a reverse Monte Carlo calculation suite, was used to fit the PDF models to two starting atomic structures. ${ }^{25}$ Using builtin packages, an amorphous S-Mo-S “molecule” was distributed in a $50 \AA^{3}$ cube filling the volume 
This is an author-produced, peer-reviewed version of this article. The final, definitive version of this document can be found online at ACS Applied Nano Materials, published by American Chemical Society. Copyright restrictions may apply. https://doi.org/10.1021/acsanm.8b00798. The content of this document may vary from the final published version.

with 1410 molecular units. The second model used the $\mathrm{MoS}_{2} 2-\mathrm{H}$ structure consisting of 10 layers of $\mathrm{MoS}_{2}$ (5 unit cells in the c direction). Each layer was extended to include 16 unit cells in $a$ and $b$ crystallographic directions. Periodic boundary conditions were enforced for both models. Bond length distributions were extracted from the atomic models generated by the fullrmc fitting procedure using the I.S.A.A.C.S. software package. ${ }^{26}$ 
This is an author-produced, peer-reviewed version of this article. The final, definitive version of this document can be found online at $A C S$ Applied Nano Materials, published by American Chemical Society. Copyright restrictions may apply. https://doi.org/10.1021/acsanm.8b00798. The content of this document may vary from the final published version.

\section{RESUltS AND DisCUSSION}

A schematic illustration of the ALD process for MoS2 and its subsequent structural transformation is shown in Figure 1. As-deposited films grown at $200{ }^{\circ} \mathrm{C}$ are shown to consist of polysulfide ion clusters and small amounts of tetragonally coordinated $\mathrm{MoS}_{2}$, as discussed below. Upon annealing at $400{ }^{\circ} \mathrm{C}$, the films develop a layered structure and evidence of ion clusters is gone by $600{ }^{\circ} \mathrm{C}$. Films annealed at $600{ }^{\circ} \mathrm{C}$ are found to exhibit a layered $2-\mathrm{H}$ phase of MoS2, but are expected to be polycrystalline with a grain size of 4-10 $\mathrm{nm}$.

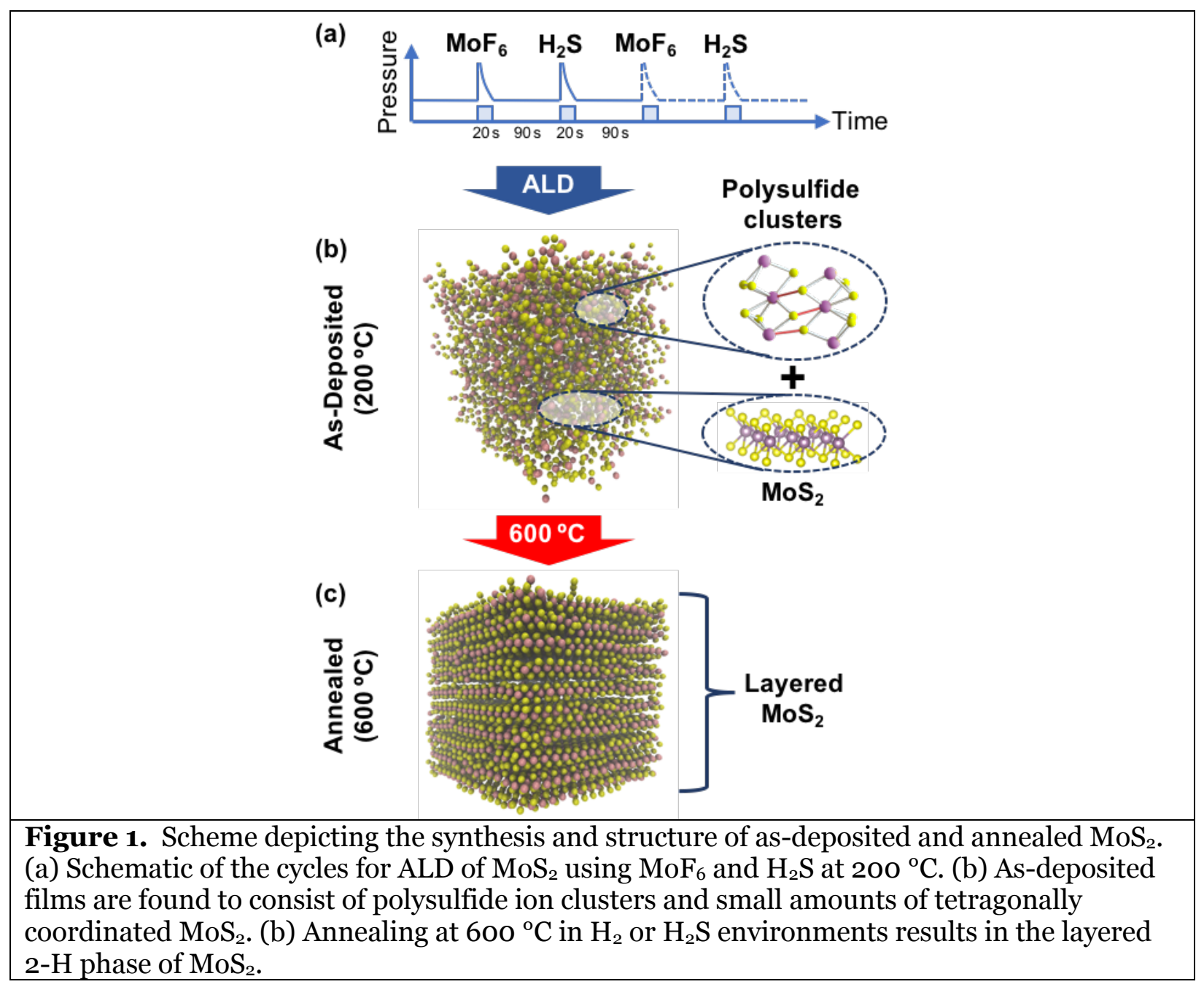


This is an author-produced, peer-reviewed version of this article. The final, definitive version of this document can be found online at ACS Applied Nano Materials, published by American Chemical Society. Copyright restrictions may apply. https://doi.org/10.1021/acsanm.8b00798. The content of this document may vary from the final published version.

Figure 2 shows Raman spectra acquired from the as-deposited $\mathrm{MoS}_{2}$ coated onto $\mathrm{CNT}-\mathrm{OH}$ powders using $50 \mathrm{ALD} \mathrm{MoS}_{2}$ cycles and after annealing treatments at $400{ }^{\circ} \mathrm{C}$ and $600{ }^{\circ} \mathrm{C}$ in $\mathrm{H}_{2}$ and $\mathrm{H}_{2} \mathrm{~S}$ environments. The as-deposited $\mathrm{MoS}_{2}$ did not show the characteristic spectra for layered $\mathrm{MoS}_{2}$, indicating that the sample was amorphous. However, the samples annealed at $400{ }^{\circ} \mathrm{C}$ in either $\mathrm{H}_{2}$ and $\mathrm{H}_{2} \mathrm{~S}$ showed small peaks associated with the in-plane and out-of-plane modes. These peaks grew in magnitude when the samples were annealed at $600{ }^{\circ} \mathrm{C}$. These results are consistent with previous reports of $\mathrm{MoS}_{2}$ ALD using other precursor combinations reported in the literature. ${ }^{10,11}$

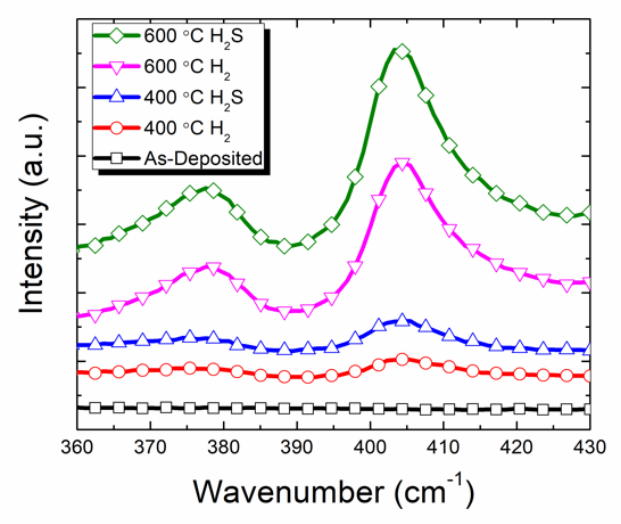

Figure 2. Raman spectra of as-deposited and annealed $\mathrm{MoS}_{2}$ films grown on CNT-OH powders. The as-deposited film lacks the characteristic Raman signals for layered $\mathrm{MoS}_{2}$, but these signals appear after annealing for $30 \mathrm{~min}$. at $400{ }^{\circ} \mathrm{C}$ and $600{ }^{\circ} \mathrm{C}$ in either $\mathrm{H}_{2} \mathrm{or}_{2} \mathrm{~S}$, indicating crystallization of the films.

Next, the $\mathrm{MoS}_{2}$ coated CNT-OH samples were dispersed onto a carbon grid and imaged in a TEM to determine the $\mathrm{MoS}_{2}$ film thickness and to investigate the morphological changes caused by annealing. Figure 3 shows TEM images recorded for the as-deposited film (Figure 3a) and after annealing at $400{ }^{\circ} \mathrm{C}$ (Figure $3 \mathrm{~b}$ ) and $600^{\circ} \mathrm{C}$ (Figure $3 \mathrm{c}$ ) in $\mathrm{H}_{2} \mathrm{~S}$. Little to no difference was observed by TEM between the films annealed in $\mathrm{H}_{2}$ and in $\mathrm{H}_{2} \mathrm{~S}$ annealing. 


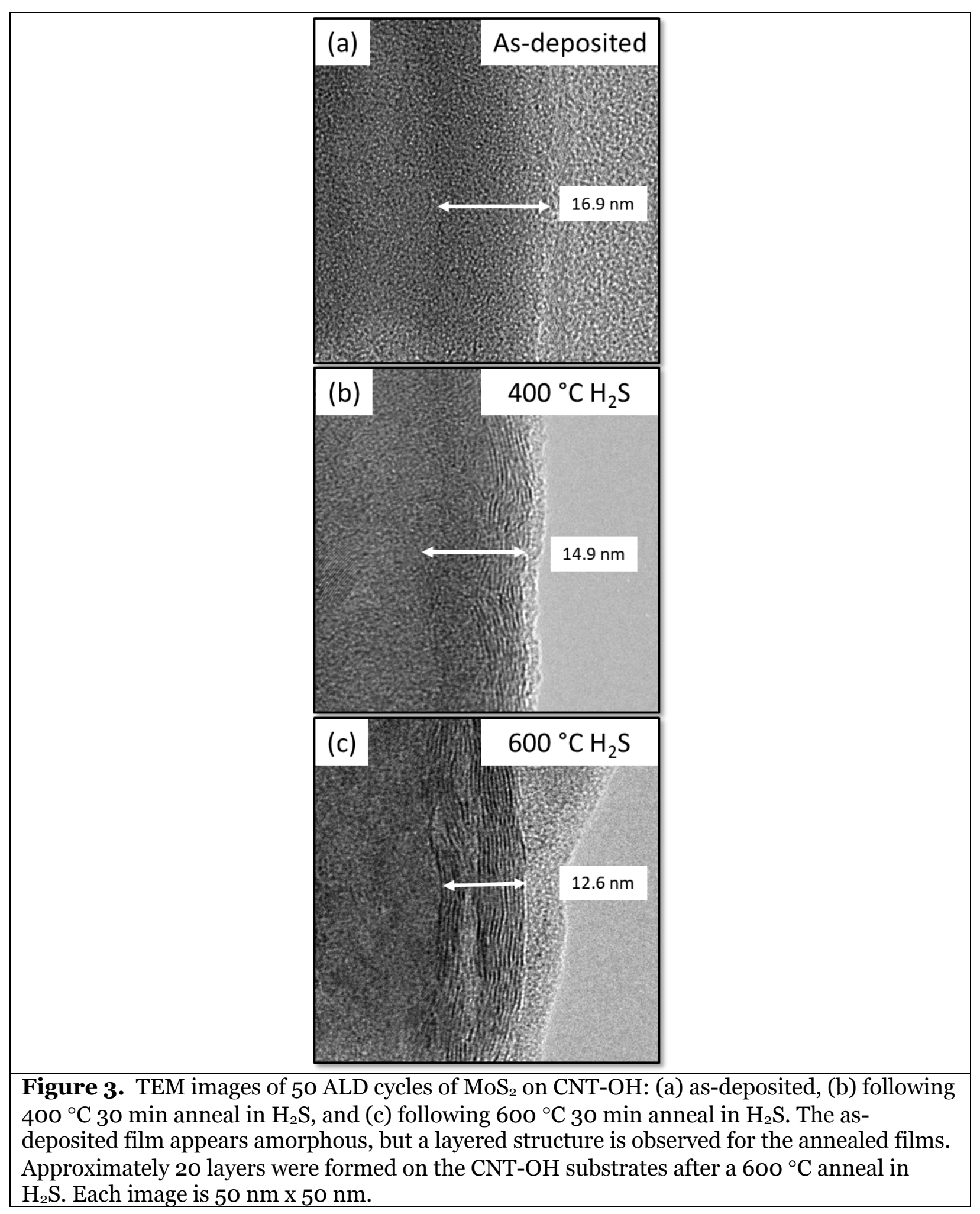


This is an author-produced, peer-reviewed version of this article. The final, definitive version of this document can be found online at $A C S$ Applied Nano Materials, published by American Chemical Society. Copyright restrictions may apply. https://doi.org/10.1021/acsanm.8b00798. The content of this document may vary from the final published version.

The as-deposited films in Figure $3 \mathrm{a}$ appear amorphous and conform well to the surface of the CNT-OH. Using the film thickness measured by TEM in Figure 3a, the growth per cycle (GPC) of the as-deposited films was determined to be $3.4 \AA$ /cycle. This is significantly higher than our previous estimate of $0.42 \AA /$ cycle based on QCM and ellipsometry measurements of films on planar samples. ${ }^{27}$ This discrepancy may result from insufficient purging of the high surface area carbon powder or from thermal decomposition of the $\mathrm{MoF}_{6}$ precursor. ${ }^{28}$ Samples annealed at 400 ${ }^{\circ} \mathrm{C}$ showed a decrease in thickness, measured by TEM, which was expected because of the crystallization of the film. Layered structures appear for samples annealed at $400{ }^{\circ} \mathrm{C}$ (Figure $3 \mathrm{~b}$ ), and samples annealed at $600{ }^{\circ} \mathrm{C}$ (Figure 3c) exhibit clear long-range crystallinity, with a clear interface between the CNT-OH surface and the $\mathrm{MoS}_{2}$. Counting the dark intensity regions of the film annealed at $600{ }^{\circ} \mathrm{C}$, approximately 20 layers were observed with a total thickness of $12.6 \mathrm{~nm}$, which is consistent with a layer thickness of $0.6 \mathrm{~nm} .{ }^{29}$ Additionally, we observe gaps between the layers of the $\mathrm{MoS}_{2}$ films annealed at $600{ }^{\circ} \mathrm{C}$. These gaps may arise because (1) the films are under stress as-deposited and this stress is relieved upon annealing leading to a separation of the layers or (2) the CNT-OH restructures or pyrolyzes and shrinks away from the $\mathrm{MoS}_{2}$ during annealing. Even after annealing at $600{ }^{\circ} \mathrm{C}$ defects are still observed. Analyzing the FFTs of the TEM micrographs, as pictured in Figure S1a-d, domains ranged from 4 to $10 \mathrm{~nm}$ in extent. The TEM results confirm our previous finding that at relatively low annealing temperatures, a layered structure is obtainable using $\mathrm{MoF}_{6}$ and $\mathrm{H}_{2} \mathrm{~S} .{ }^{27}$

To further characterize the as-deposited films, XAFS data from the Mo K absorption edge (20 $\mathrm{keV}$ ) were obtained for 200 cycle $\mathrm{MoS}_{2}$ films grown on $\mathrm{Al}_{2} \mathrm{O}_{3}$ powder. Measurements were carried out in fluorescence mode with an energy dispersive Vortex detector with an energy out to $11.8 \AA^{-}$ 1. Figure 4 shows XAS spectra for three measured conditions, including a $\mathrm{MoS}_{2}$ powder reference sample. Our previous report of $\mathrm{MoS}_{2} \mathrm{ALD}$ using $\mathrm{MoF}_{6}$ and $\mathrm{H}_{2} \mathrm{~S}$ found $\sim 16 \%$ oxygen in the films, which was thought to arise from reaction with ambient moisture when the samples were removed 
from the reactor at the $200{ }^{\circ} \mathrm{C}$ growth temperature. ${ }^{27}$ To reduce this effect, we cooled the ALD reactor down to $\sim 40{ }^{\circ} \mathrm{C}$ before removing the samples into the air. XPS of the as-deposited films (Figure S2a) indeed revealed oxygen peaks consistent with $\mathrm{MoO}_{\mathrm{x}}$ species. However, given the extreme surface sensitivity of the XPS, we attribute this primarily to surface oxidation, which would be enhanced on a high surface area powder. If the ALD-grown $\mathrm{MoS}_{2}$ films contained $\mathrm{MoO}_{2}$ and $\mathrm{MoO}_{3}$, we would expect to see signature features of these phases in the X-ray absorption near edge (XANES) region (Figure 4). ${ }^{30,31}$ However, we found that the ALD-grown $\mathrm{MoS}_{2}$ lacked the preedge feature of $\mathrm{MoO}_{3}$ and lacked white-line features that would indicate $\mathrm{MoO}_{2} \cdot{ }^{30,3^{1}}$ The absence of these features and the good agreement with the $\mathrm{MoS}_{2}$ reference indicate that our films had minimal oxygen content.

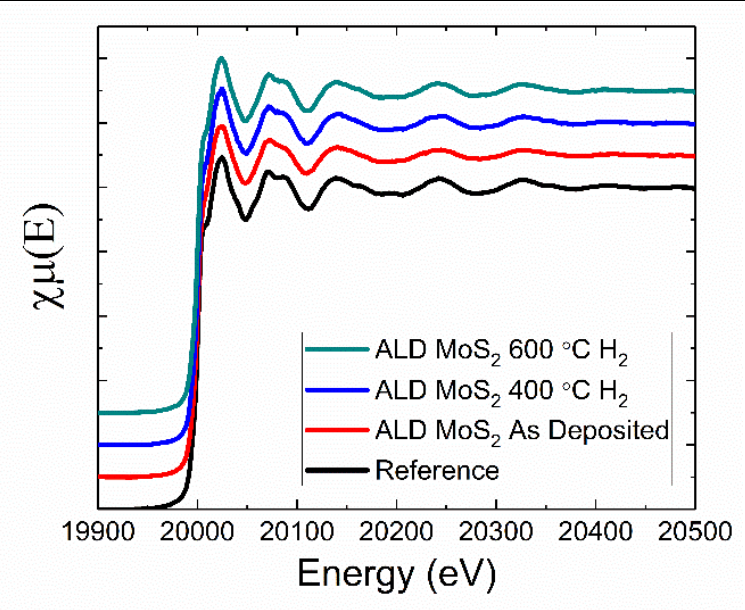

Figure 4. X-ray absorption spectra of the Mo K edge for each as-deposited $\mathrm{MoS}_{2}$ on alumina powder and for annealed films. The spectrum of a $\mathrm{MoS}_{2}$ reference powder is included for comparison. The data indicate a lack of molybdenum oxide species.

As outlined in the introduction, many of the as-deposited ALD $\mathrm{MoS}_{2}$ films lack or have very weak 2D Raman peaks. This suggests that the as-deposited ALD films lack a layered structure. The XAS measurements can give information about the atomic coordination spheres smaller than the basal planes of $\mathrm{MoS}_{2}(\sim 6 \AA)$. To examine the coordination spheres of Mo, the XAS spectra were 
transformed to yield real space $(|\mathrm{X}(\mathrm{R})|)$ radial distribution plots (Figure $5 \mathrm{a})$ and k-space plots of the scattering amplitudes (Figure 5b). Two features are clearly visible in the real space scattering intensity (Figure 5a) for the as-deposited and annealed films and the $\mathrm{MoS}_{2}$ powder reference. Theoretical ab initio scattering calculations performed with FEFF, ${ }^{32}$ using the $\mathrm{MoS}_{2} 2-\mathrm{H}$ structure, indicate that the first feature is associated with the Mo-S pair peak (1.4 to $2.3 \AA$ ) while the second feature arises from the Mo-Mo pair peak (2.3 to $3.3 \AA$ )..$^{32,33}$ The k-space plots of the scattering amplitudes in Figure 5b show that much of the difference between the samples occurs in the higher $\mathrm{k}$ range, which is where the Mo-Mo contribution is the largest.
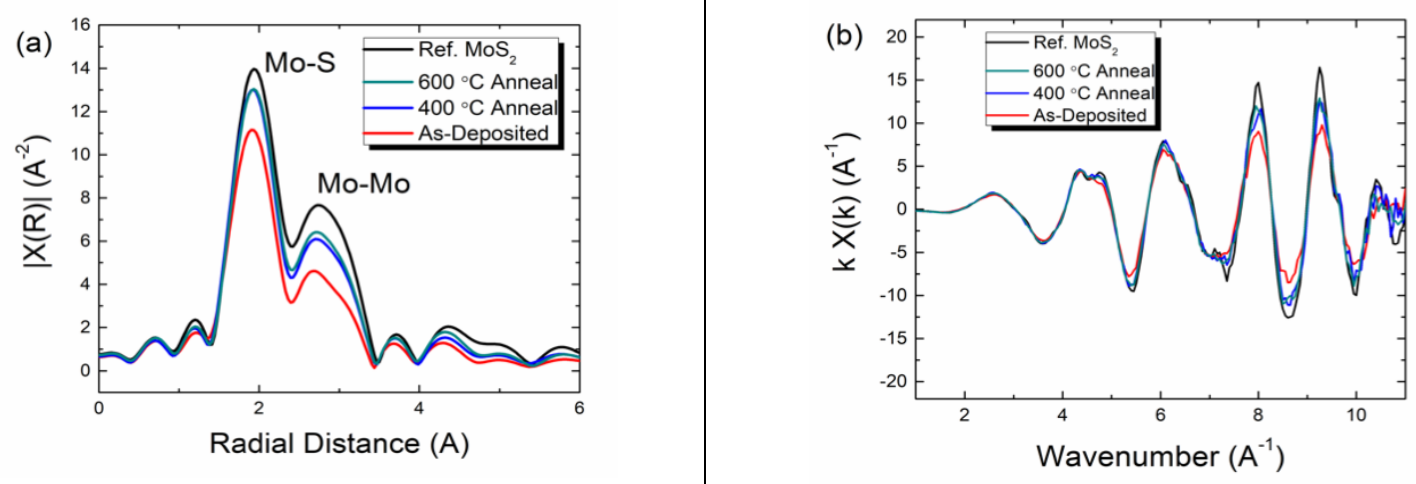

Figure 5. Analyzed XAS data showing the (a) radial distribution of the scattering intensity around molybdenum and (b) the reciprocal space scattering amplitudes.

Qualitative observations from the XAS data indicate that the Mo-S and Mo-Mo coordination increases dramatically for the samples annealed at 400 and $600{ }^{\circ} \mathrm{C}$ when compared to the asdeposited film, but the difference between the two annealing conditions is minimal. At higher wavenumbers in Figure 5b, we see an increase in peak intensity for the annealed $\mathrm{MoS}_{2}$ films, which indicates an increase in crystallinity. However, none of the ALD films approach the scattering intensity of the reference, suggesting that the $\mathrm{MoS}_{2}$ films still contain disorder. A lack of splitting of the Mo-Mo peak suggests that the primary phase of the annealed samples is tetragonally coordinated (2-H) rather than octahedrally coordinated (1-T).34,35 
This is an author-produced, peer-reviewed version of this article. The final, definitive version of this document can be found online at ACS Applied Nano Materials, published by American Chemical Society. Copyright restrictions may apply. https://doi.org/10.1021/acsanm.8b00798. The content of this document may vary from the final published version.

To quantify the atomic structural changes during annealing, we fitted the XAFS data using the first two coordination shells of Mo. This fit was carried out using the Artemis software package. ${ }^{23}$ Using the bulk $\mathrm{MoS}_{2}$ and the 2-H $\mathrm{MoS}_{2}$ structure, we determined the amplitude reduction factor, $\mathrm{SO}^{2}$, to be 0.8 . This value was use for the as-deposited and annealed samples. Fitting the first two single scattering peaks in Figure 5, which correspond to Mo-S and Mo-Mo, we can start to understand the atomic structural changes during annealing. A summary of the scattering distances is provided in Table S1, and Figure 6 is a plot of the coordination numbers determined from XAFS modeling for the as-deposited and annealed $\mathrm{MoS}_{2}$ films. The Mo-S coordination numbers of the samples annealed at $400{ }^{\circ} \mathrm{C}$ and $600{ }^{\circ} \mathrm{C}$ are very similar to the standard, while the Mo-Mo coordination number of the ALD samples is significantly lower than the bulk $\mathrm{MoS}_{2}$ reference. We found that the Mo coordination is as small as 2.8 for as-deposited ALD MoS $\mathrm{M}_{2}$ and when annealed in $\mathrm{H}_{2}$, the Mo-Mo coordination number increased to approximately 4.3. This is still quite low when compared to the theoretical value of six; however, the reference is also lower than this theoretical value. An explanation could be a consequence of the small grain sizes of the samples and scattering contributions from edge defects. Interestingly, we observe only a small increase in the Mo-Mo coordination number when increasing the annealing temperature from 400 to $600{ }^{\circ} \mathrm{C}$. Based on the low Mo-Mo coordination, we predict that the in-plane structure is disordered. This is most likely causing the asymmetry in the Raman spectra (Figure 2), which is similarly found in ion damaged films. ${ }^{36}$ Scattering from phonon modes in disordered films also leads to asymmetry in the Raman $\mathrm{E}_{2 \mathrm{~g}}$ peaks for ALD films. ${ }^{12}$ Disorder is visible in Figure $3 \mathrm{c}$ as many of the $\mathrm{MoS}_{2}$ layers are discontinuous. Improvements, either by surface nucleation control, longer annealing times, or higher temperatures, will need to be explored if the ALD $\mathrm{MoS}_{2}$ is to exhibit the high carrier mobilities observed for CVD grown films since defects in layered $\mathrm{MoS}_{2}$ strongly impact its properties. ${ }^{37,38}$ 


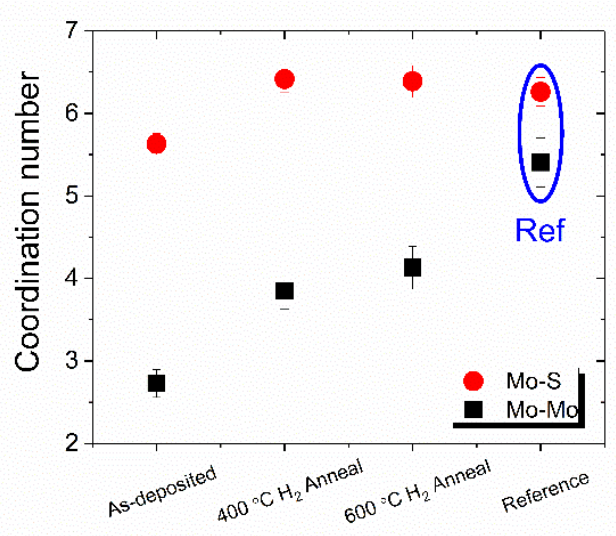

Figure 6. Coordination numbers of the Mo-S and Mo-Mo single scattering lengths for the asdeposted and annealed $\mathrm{MoS}_{2}$ films, as well as a bulk $\mathrm{MoS}_{2}$ reference. Low Mo-Mo coordination is observed for the as-deposited film, but anneling to $600{ }^{\circ} \mathrm{C}$ only increased the coordination to $\sim 4$. Mo-S coordination was observed to be close to the ideal value of 6 for all growth conditions.

To further understand the structures of the ALD films, transmission high-energy x-ray diffraction measurements were obtained. The sample-detector distance and the beam center were set to maximize the diffraction angle or $\mathrm{Q}$ range by calibrating to a $\mathrm{NIST}^{\mathrm{CeO}_{2}}$ powder. In these experiments, we changed the growth substrate to a lower atomic number material: hydroxylated carbon nanotubes. Not only do they have lower atomic number than the alumina powder, but have a small background, which is easily subtracted for data analysis. Because of the increase in surface area, we decreased the number of ALD cycles from 200, as used for the XAS measurements, to 50 total ALD cycles. In these experiments, we additionally used $\mathrm{H}_{2} \mathrm{~S}$ as a reducing agent when annealing the powders. Using the GSASII software package, a full integration $\left(360^{\circ}\right)$ was used..$^{24}$ The beam stop limited our low $Q$ range to $\sim 0.7 \AA^{-1}$ and integrated out to $32 \AA^{-1}$. Again, GSASII was used to compute pair distribution functions (PDFs) from the diffraction data, Fourier transforms were performed and were optimized for the as-deposited films, and the optimized parameters were used for all other fits. Figure $7 \mathrm{a}$ and $\mathrm{b}$ compare normalized PDFs for the full distance ranges for both the $\mathrm{H}_{2}$ and $\mathrm{H}_{2} \mathrm{~S}$ annealing conditions, respectively. 


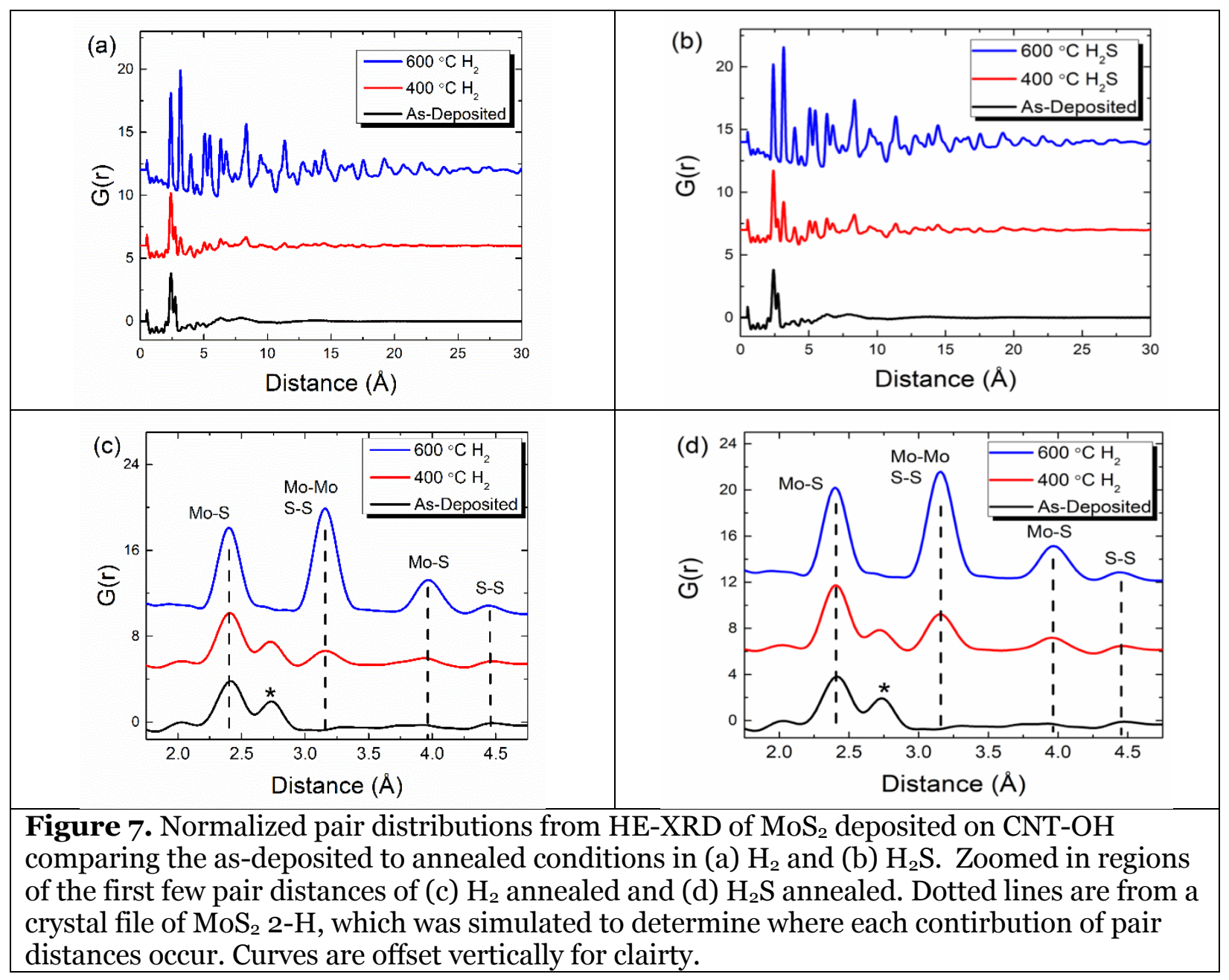

Our PDF measurements of the as-deposited $\mathrm{MoS}_{2}$ films (Figure $7 \mathrm{a}$ and b) are essentially featureless at atomic pair distances $>5 \AA$, and this is consistent with the films being X-ray amorphous. ${ }^{27} \mathrm{~A}$ clear increase in crystallinity is apparent for the $400{ }^{\circ} \mathrm{C}$ anneal in both $\mathrm{H}_{2}$ and $\mathrm{H}_{2} \mathrm{~S}$, as features appear at atomic pair distances $>5 \AA$. Sharper features at larger pair distances for the samples annealed at $600^{\circ} \mathrm{C}$ in Figure $7 \mathrm{a}$ and $\mathrm{b}$ indicate further crystallization. Figure7c and $\mathrm{d}$ show expanded views of the PDF data between 1 and $5 \AA$, where the scattering bonding pairs associated with the peaks are labeled and dotted lines indicate the ideal positions from the $\mathrm{MoS}_{2}$ 2-H structure. The as-deposited films seem to show only a Mo-S pair peak as well as an unidentified peak at a pair distance of approximately $2.74 \AA$. This result could be explained by the 
This is an author-produced, peer-reviewed version of this article. The final, definitive version of this document can be found online at $A C S$ Applied Nano Materials, published by American Chemical Society. Copyright restrictions may apply. https://doi.org/10.1021/acsanm.8b00798. The content of this document may vary from the final published version.

presence of $\left[\mathrm{Mo}_{3} \mathrm{~S}\left(\mathrm{~S}_{2}\right)_{6}\right]^{2-}$ ion clusters $(\mathrm{Mo}-\mathrm{Mo}=2.72 \AA)$ or $\mathrm{MoS}_{3}(\mathrm{Mo}-\mathrm{Mo}=2.745 \AA)$, which were seen previously in amorphous $\mathrm{MoS}_{3}$ films.39,40 Previously, we proposed that $\mathrm{MoS}_{3}$ might be the thermodynamically stable product from $\mathrm{MoF}_{6} / \mathrm{H}_{2} \mathrm{~S}$ ALD. ${ }^{27}$ In both $\left[\mathrm{Mo}_{3} \mathrm{~S}\left(\mathrm{~S}_{2}\right)_{6}\right]^{2-}$ and $\mathrm{MoS}_{3}$, Mo sits in a $4^{+}$state, making it difficult, from the Mo 3 d region in XPS, to determine which phase is most likely to cause the $2.74 \AA$ peak in Figure $7 \mathrm{c}$ and d. The S 2p XPS scan of the as-deposited sample (Figure S2b) showed two distinct sulfur binding states: $\mathrm{S}^{2-}$ and $\mathrm{S}_{2}{ }^{-2}$, which would make $\mathrm{MoS}_{2}$ less likely as this exhibits only a single sulfur environment. ${ }^{11}$ Proposed structures of amorphous $\mathrm{MoS}_{3}$ from XAFS data have shown two Mo-Mo pair peaks at 2.746 and 3.158 $\AA .39$ The lack of this pair distance in the PDF data would support the proposed $\left[\mathrm{Mo}_{3} \mathrm{~S}\left(\mathrm{~S}_{2}\right)_{6}\right]^{2-}$ structure as the most likely phase present. In addition, Mo has 7-fold coordination to $\mathrm{S}$ in these clusters, which could explain the Mo-S coordination numbers > 6 measured above in the XAS data. Unfortunately, attempts to incorporate this scattering length into the model failed to improve the fit of the XAS data. After annealing at $400{ }^{\circ} \mathrm{C}$, the samples show small peaks that match well with the $\mathrm{MoS}_{2}$ structure, and a small peak arising from the clusters is still present. After annealing at $600{ }^{\circ} \mathrm{C}$, the peak at $2.74 \AA$, which we attribute to $\left[\mathrm{Mo}_{3} \mathrm{~S}\left(\mathrm{~S}_{2}\right)_{6}\right]^{2-}$ clusters, disappears, and a wellformed $\mathrm{MoS}_{2}$ structure is obtained. However, if the under-coordination of Mo-Mo is an indication of the $\left[\mathrm{Mo}_{3} \mathrm{~S}\left(\mathrm{~S}_{2}\right)_{6}\right]^{2-}$ clusters, then the XAS data in Figure 7 indicates that some clustering is still present following annealing at $600{ }^{\circ} \mathrm{C}$.

Reverse Monte Carlo fitting (fullrmc software ${ }^{25}$ ) was used to analyze the PDF data further in order to better define the ALD $\mathrm{MoS}_{2}$ structures. We chose two structures as our input: an amorphous structure, notated as (a), made up of $1410 \mathrm{MoS}_{2}$ molecular units in a $50 \AA^{3}$ volume, and a crystalline structure, notated as (c), starting with a 2-H unit cell, which was expanded into a larger supercell. The amorphous and crystalline structures are depicted in Figure8a and b, respectively. 


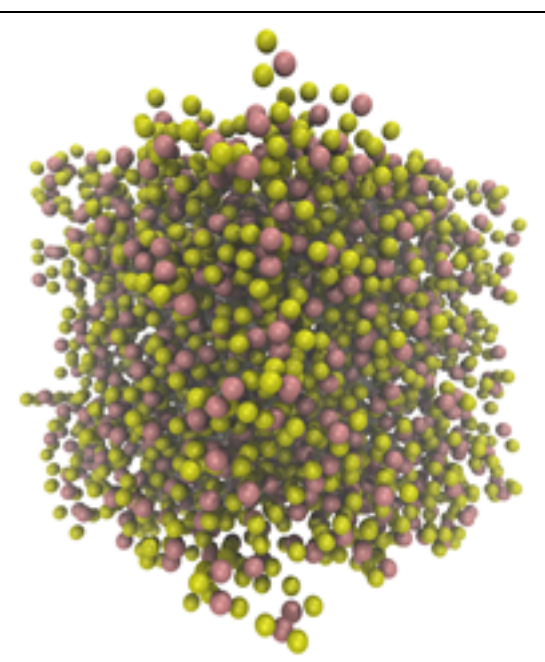

(a)

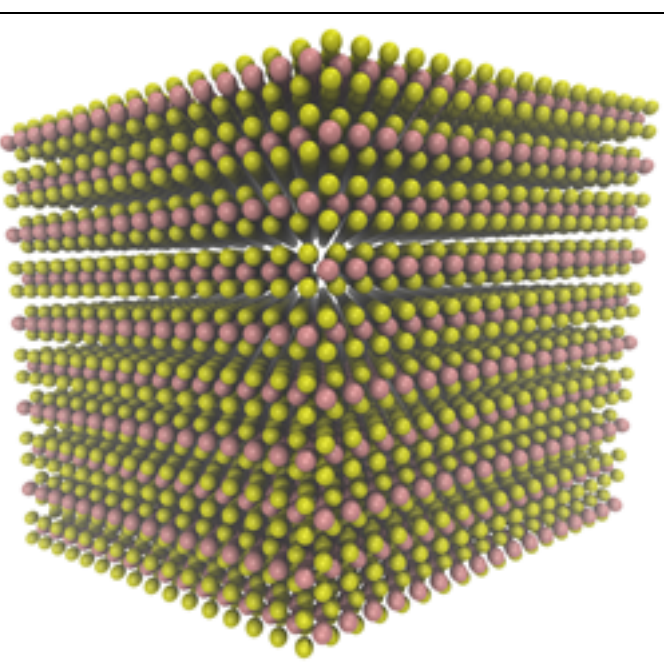

(b)

Figure 8. Images of the starting models used as input structures for fullrmc for the (a) amorphous and (b) crystalline (2-H phase) $\mathrm{MoS}_{2}$ films. Both super cells fill a $50 \AA^{3}$ volume. Yellow spheres represent sulfur while the violet spheres are molybdenum.

Using these starting structures, we optimized the atomic positions to fit our experimental PDF data using translations, swaps, and removes. Translations used a step size of $0.1 \AA$ and the number of accepted moves was set to $2.7 \times 10^{7}$. We compared the coordination numbers, $\mathrm{CN}$, from our model fits to the XAS data as a check of the validity of the models as outlined in Table $\mathbf{1}$.

Table 1. Fitting parameters and coordination numbers from RMC models of both amorphous and crystalline $\mathrm{MoS}_{2}$ labeled $a$ and $c$ respectively.

\begin{tabular}{|c|c|c|c|c|c|c|c|c|c|c|}
\hline & \multicolumn{2}{|c|}{ As-deposited } & \multicolumn{2}{|c|}{$400^{\circ} \mathrm{C} \mathrm{H}_{2}$} & \multicolumn{2}{|c|}{$400^{\circ} \mathrm{C} \mathrm{H}_{2} \mathrm{~S}$} & \multicolumn{2}{|c|}{$600^{\circ} \mathrm{C} \mathrm{H}_{2}$} & \multicolumn{2}{|c|}{$600^{\circ} \mathrm{C} \mathrm{H}_{2} \mathrm{~S}$} \\
\hline & a & c & a & $\mathrm{c}$ & $\mathrm{a}$ & $\mathrm{c}$ & $\mathrm{a}$ & $\mathrm{c}$ & a & c \\
\hline$\chi^{2}$ & 56.48 & 61.02 & 52.34 & 47.57 & 67.04 & 48.84 & 278.13 & 71.45 & 247.09 & 65.99 \\
\hline Mo-Mo CN & 1.94 & 3.46 & 2.23 & 3.66 & 2.11 & 4.18 & 1.91 & 4.82 & 1.95 & 4.86 \\
\hline Mo-S CN & 2.46 & 6.00 & 2.23 & 5.84 & 2.25 & $5 \cdot 75$ & 2.18 & 5.08 & 2.21 & 5.17 \\
\hline
\end{tabular}

The fit parameter, $\chi^{2}$, is an indication of the quality of fit, with lower values indicating a better fit.

For the as-deposited film, $\chi^{2}$ is lower for the amorphous structure compared to the crystalline structure, indicating that the amorphous structure better represents the as-deposited $\mathrm{MoS}_{2}$. In contrast, $\chi^{2}$ is lower for the crystalline structure compared to the amorphous structure for all the 
This is an author-produced, peer-reviewed version of this article. The final, definitive version of this document can be found online at $A C S$ Applied Nano Materials, published by American Chemical Society. Copyright restrictions may apply. https://doi.org/10.1021/acsanm.8b00798. The content of this document may vary from the final published version.

annealed samples, indicating that the crystalline structure better represents the annealed $\mathrm{MoS}_{2}$.

We also note that $\chi^{2}$ increases dramatically for the amorphous structure at $600^{\circ} \mathrm{C}$, indicating a very poor fit.

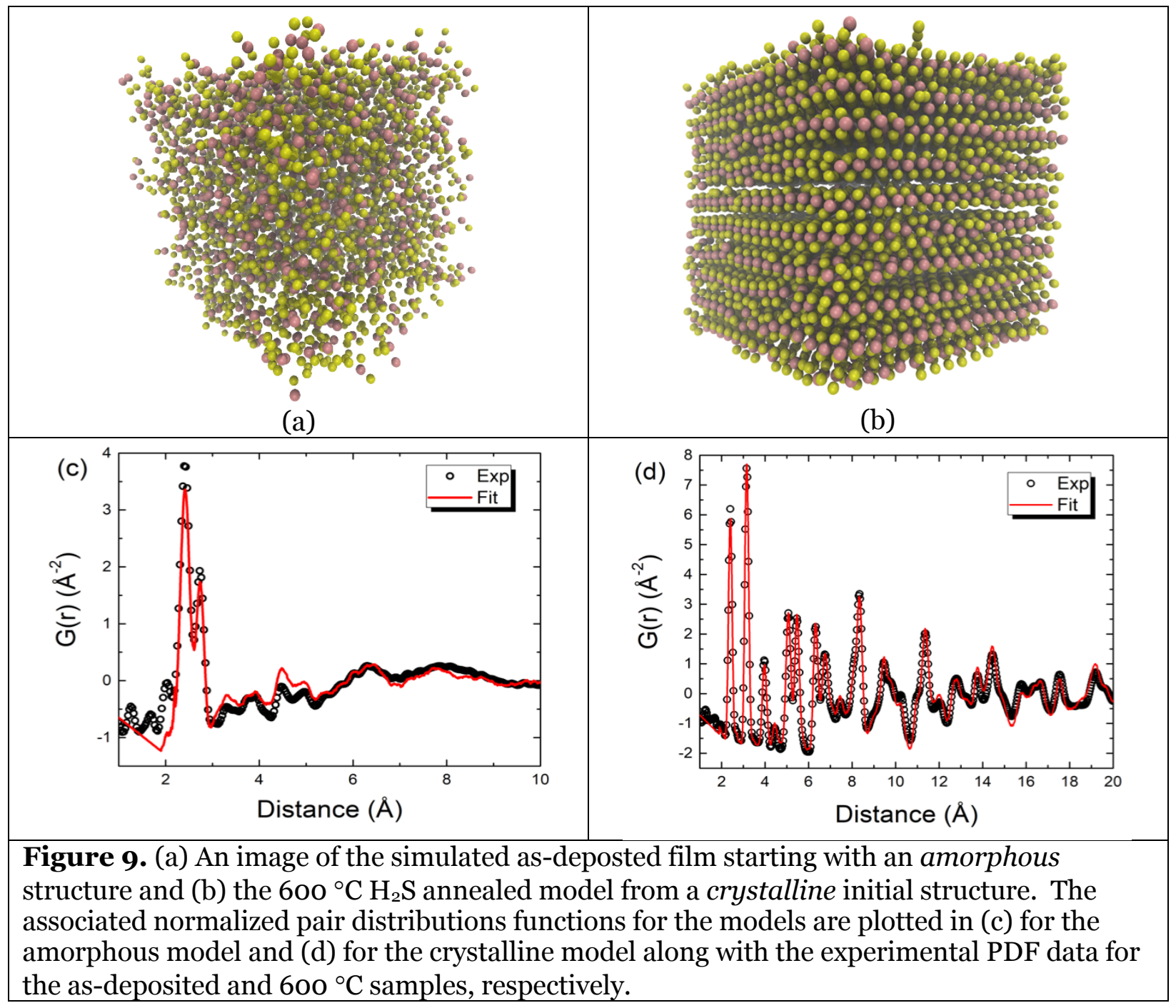

The resulting fits and models for the PDF data are shown in Figure 9. Figure 9a and b show the final structures for the as-deposited and $600{ }^{\circ} \mathrm{C} \mathrm{H}_{2} \mathrm{~S}$ films, respectively. Little difference is visible between the amorphous input model (Figure 8a) and output model (Figure 9a). This similarity was not surprising as only local variations in the atomic structures were observed when fitting the experimental data for the as-deposited film with the amorphous structure in Figure 9c. However, 
This is an author-produced, peer-reviewed version of this article. The final, definitive version of this document can be found online at ACS Applied Nano Materials, published by American Chemical Society. Copyright restrictions may apply. https://doi.org/10.1021/acsanm.8b00798. The content of this document may vary from the final published version.

long-range structural coherence can be seen after fitting the experimental data for the annealed film with the periodic structure in Figure 9d. Interestingly, the model of the annealed film (Figure 9b) exhibits collective movement visible as bending of the layers, which could be an artifact of the ALD $\mathrm{MoS}_{2}$ growing on the small multi-walled nano-tubes or defects in the layers. Both bending and 2D defects are also visible by TEM in Figure 3c.

Next, we used the software package I.S.A.A.C.S. to extract bond length distributions from the atomic models derived from the fullrmc fitting procedure in Figure $9 .^{26}$ This process helps visualize the individual atom pair distributions that contribute to the overall signals in the PDF data. For instance, the peak at 3.1 $\AA$ in Figure $7 \mathrm{c}$ and d arises from a combination of Mo-Mo and S-S bond pairs. For the as-deposited films, the minimized amorphous model was used as the input structure, while for all annealed films the minimized crystalline structure was used. Figure 10a shows the distributions of nearest neighbors for the Mo-Mo pairs. The as-deposited film has a large, broad distribution starting at about 2.3 $\AA$ to 2.9 $\AA$; however, molybdenum metal has a pair distance of 2.7 $\AA$, which would suggest that any value below this is nonsensical and a consequence of the fitting procedure (the fullrmc algorithm was set to accept $30 \%$ of rejected translations/swaps/removes). Ignoring the data below the $2.7 \AA$, interestingly, the Mo-Mo distances are forced to much lower values matching closely to the $\left[\mathrm{Mo}_{3} \mathrm{~S}\left(\mathrm{~S}_{2}\right)_{6}\right]^{2-}$ clusters $(\sim 2.8 \AA)$ proposed above with little to no $\mathrm{MoS}_{2} \cdot 39$

The as-deposited Mo-S pairs (Figure 10b) exhibit two distributions, which we attribute to the $\left[\mathrm{Mo}_{3} \mathrm{~S}\left(\mathrm{~S}_{2}\right)_{6}\right]^{2-}$ clusters. The values match well with the initial XAFS and proposed models.39,42 Figure 10c shows the S-S distribution and exhibits two bond distributions for the as-deposited films. To our knowledge, no published data has reported the S-S pair distances in amorphous $\mathrm{MoS}_{2}$. In $\mathrm{WSe}_{2}, \mathrm{NbSe}_{2}$, and $\mathrm{MoSe}_{2}$, the Se-Se pair distance is approximately $2.4 \AA$, 39 which matches well with the broad peaks at 2.4 $\AA$ in Figure 10c. Persulfides have been proposed in ion clusters and amorphous structure before, ${ }^{39,42}$ which would have a bond distance of $\sim 2.0 \AA$, as in 
This is an author-produced, peer-reviewed version of this article. The final, definitive version of this document can be found online at ACS Applied Nano Materials, published by American Chemical Society. Copyright restrictions may apply. https://doi.org/10.1021/acsanm.8b00798. The content of this document may vary from the final published version.

elemental sulfur.43 XAS measurements using the $\mathrm{S}$ k-edge could help determine the distribution, however we are most likely observing the two pair distances in the ion clusters.

From the PDF analysis, we predict an as-deposited structure that is a mixture of $\mathrm{MoS}_{2}$ and $\left[\mathrm{Mo}_{3} \mathrm{~S}\left(\mathrm{~S}_{2}\right)_{6}\right]^{2-}$. In both of these species, Mo has a $4^{+}$oxidation, which argues against the existence of $\mathrm{MoS}_{3}$. Our previous study of $\mathrm{MoS}_{2} \mathrm{ALD}$ found the films to be sulfur deficient, ${ }^{27}$ which we suspect to indicate Mo-Mo bonding, or Mo metal clusters, in the structure. The discrepancy to previous work is most likely caused by the long dose times and high surface area substrates used in the current study. These results suggest that the deposition rate and composition is strongly dependent on by-product formation. This deviation from ideal ALD behavior may allow for control of the composition and stoichiometry of the as-deposited films.

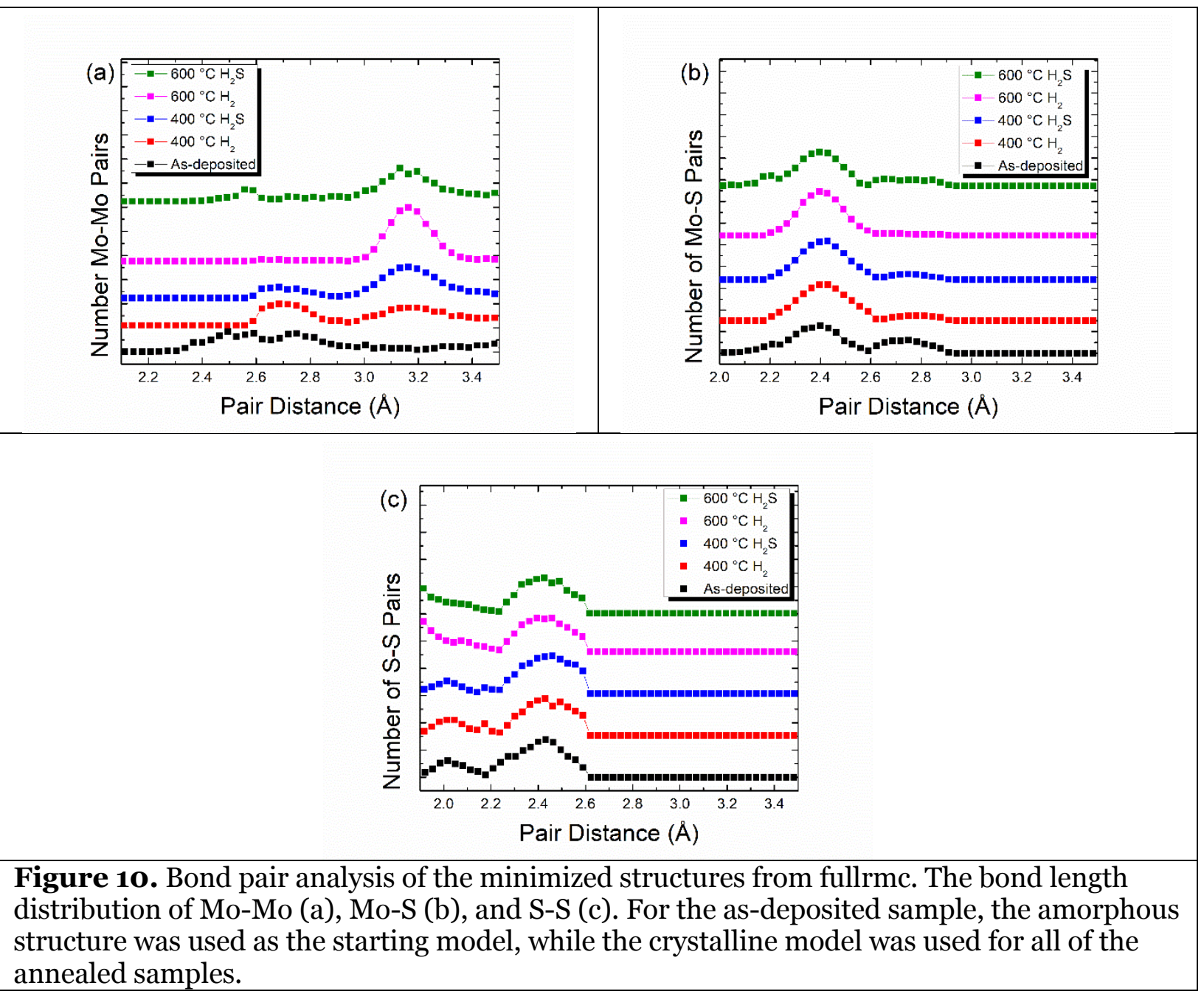




\section{Conclusions}

ALD $\mathrm{MoS}_{2}$ was deposited on both $\mathrm{Al}_{2} \mathrm{O}_{3}$ and CNT-OH powders and analyzed with XAS and HEXRD measurements. Complementary TEM and Raman measurements demonstrated that the asdeposited were amorphous, but after annealing at $600{ }^{\circ} \mathrm{C}$ in $\mathrm{H}_{2}$ or $\mathrm{H}_{2} \mathrm{~S}$, TEM revealed a layered structure, and Raman spectroscopy indicated a crystalline film. Analyzing the XAFS data, the MoS and Mo-Mo coordination's were determined. In the as-deposited films, the Mo-Mo coordination was smaller than theoretical models, while the Mo-S coordination number was larger. PDF analysis confirmed an amorphous structure and indicated the presence of $\left[\mathrm{Mo}_{3} \mathrm{~S}\left(\mathrm{~S}_{2}\right)_{6}\right]^{2-}$ clusters. This was supported by XPS and RMC modeling, which indicated polysulfides forming in the clusters. The clusters are close to a $\mathrm{MoS}_{3}$ structure, but our findings agree with Mo being in a $4^{+}$ oxidation state, as found in our prior work. These cluster structures begin to transform into $\mathrm{MoS}_{2}$ at $400{ }^{\circ} \mathrm{C}$ and disappear after annealing to $600{ }^{\circ} \mathrm{C}$. Our previous work indicated a sulfur deficient film, contrasting the results reported here, and we attribute this discrepancy to precursor stability and by-product interactions in the high surface area substrates used here. Adjusting dose and purge times, a near stoichiometric as-deposited $\mathrm{MoS}_{2}$ film should be attainable, with crystallization to a layered structure after annealing at relatively low temperatures. 


\section{SUPPORTING INFORMATION}

Analysis of TEM image of $\mathrm{MoS}_{2}$ on CNT-OH. Analysis of XPS data for $\mathrm{MoS}_{2}$ on CNT-OH. XAFS data analysis.

\section{ACKNOWLEDGMENTS}

This work was supported as part of the Center for Electrochemical Energy Science, an Energy Frontier Research Center funded by the U.S. Department of Energy (DOE), Office of Science, Office of Basic Energy Sciences. S.L. acknowledges support from the U.S. Department of Energy, Office of Science, Office of Workforce Development for Teachers and Scientists, Office of Science Graduate Student Research (SCGSR) program. The SCGSR program is administered by the Oak Ridge Institute for Science and Education for the DOE under Contract No. DE-SCo014664. The XAS and HE-XRD experiments used resources at the 11-1D-C and 10-BM of the Advanced Photon Source, a U.S. Department of Energy (DOE) Office of Science User Facility operated for the DOE Office of Science by Argonne National Laboratory under Contract No. DE-ACo2-06CH11357. 10$\mathrm{BM}$ is operated by the Materials Research Collaborative Access Team, which is supported by the DOE and its member institutions. We would like to thank John Katsoudas for his assistance with experiments at 10-BM. Use of the Center for Nanoscale Materials, an Office of Science user facility, was supported by the U.S. Department of Energy, Office of Science, Office of Basic Energy Sciences, under Contract No. DE-AC02-06CH11357. 


\section{REFERENCES}

(1) Tan, C.; Cao, X.; Wu, X.-J.; He, Q.; Yang, J.; Zhang, X.; Chen, J.; Zhao, W.; Han, S.; Nam, G.-H.; et al. Recent Advances in Ultrathin Two-Dimensional Nanomaterials. Chem. Rev. 2017, 117 (9), 6225-6331.

(2) Radisavljevic, B.; Radenovic, A.; Brivio, J.; Giacometti, V.; Kis, A. Single-Layer $\mathrm{MoS}_{2}$ Transistors. Nat. Nanotechnol. 2011, 6 (3), 147-150.

(3) Coy Diaz, H.; Avila, J.; Chen, C.; Addou, R.; Asensio, M. C.; Batzill, M. Direct Observation of Interlayer Hybridization and Dirac Relativistic Carriers in Graphene/ $\mathrm{MoS}_{2}$ van Der Waals Heterostructures. Nano Lett. 2015, 15 (2), 1135-1140.

(4) Pierucci, D.; Henck, H.; Avila, J.; Balan, A.; Naylor, C. H.; Patriarche, G.; Dappe, Y. J.; Silly, M. G.; Sirotti, F.; Johnson, A. T. C.; et al. Band Alignment and Minigaps in Monolayer $\mathrm{MoS}_{2}-$ Graphene van Der Waals Heterostructures. Nano Lett. 2016, 16 (7), 4054-4061.

(5) George, S. M. Atomic Layer Deposition: An Overview. Chem. Rev. 2o10, 110 (1), 111-131.

(6) Suntola, T.; Antson, J. US Patent 4058430 (1977). Google Sch. 1996.

(7) Nishizawa, J.-I.; KurabayashI, T. Photo-Assisted Molecular Layer Epitaxy. MRS Proc. 1987, 101, 275.

(8) Nishizawa, J.; Kurabayashi, T.; Abe, H.; Nozoe, A. Mechanism of Surface Reaction in GaAs Layer Growth. Surf. Sci. 1987, 185 (1-2), 249-268.

(9) Leskelä, M.; Kemell, M.; Kukli, K.; Pore, V.; Santala, E.; Ritala, M.; Lu, J. Exploitation of Atomic Layer Deposition for Nanostructured Materials. Mater. Sci. Eng. C 2007, 27 (58), 1504-1508.

(10) Tan, L. K.; Liu, B.; Teng, J. H.; Guo, S.; Low, H. Y.; Loh, K. P. Atomic Layer Deposition of a $\mathrm{MoS}_{2}$ Film. Nanoscale 2014, 6 (18), 10584-10588.

(11) Jin, Z.; Shin, S.; Kwon, D. H.; Han, S.-J.; Min, Y.-S. Novel Chemical Route for Atomic Layer Deposition of $\mathrm{MoS}_{2}$ Thin Film on $\mathrm{SiO}_{2} / \mathrm{Si}$ Substrate. Nanoscale 2014, 6 (23), 1445314458.

(12) Jurca, T.; Moody, M. J.; Henning, A.; Emery, J. D.; Wang, B.; Tan, J. M.; Lohr, T. L.; Lauhon, L. J.; Marks, T. J. Low-Temperature Atomic Layer Deposition of $\mathrm{MoS}_{2}$ Films. Angew. Chemie Int. Ed. 2017, 56 (18), 4991-4995.

(13) Mattinen, M.; Hatanpää, T.; Sarnet, T.; Mizohata, K.; Meinander, K.; King, P. J.; Khriachtchev, L.; Räisänen, J.; Ritala, M.; Leskelä, M. Atomic Layer Deposition of Crystalline $\mathrm{MoS}_{2}$ Thin Films: New Molybdenum Precursor for Low-Temperature Film Growth. Adv. Mater. Interfaces 2017, 1700123, 1700123.

(14) Cadot, S.; Renault, O.; Frégnaux, M.; Rouchon, D.; Nolot, E.; Szeto, K.; Thieuleux, C.; Veyre, L.; Okuno, H.; Martin, F.; et al. A Novel 2-Step ALD Route to Ultra-Thin $\mathrm{MoS}_{2}$ Films on $\mathrm{SiO}_{2}$ through a Surface Organometallic Intermediate. Nanoscale 2017, 9 (2), 538-546.

(15) Li, H.; Zhang, Q.; Yap, C. C. R.; Tay, B. K.; Edwin, T. H. T.; Olivier, A.; Baillargeat, D. From Bulk to Monolayer $\mathrm{MoS}_{2}$ : Evolution of Raman Scattering. Adv. Funct. Mater. 2012, 22 (7), 1385-1390. 
This is an author-produced, peer-reviewed version of this article. The final, definitive version of this document can be found online at $A C S$ Applied Nano Materials, published by American Chemical Society. Copyright restrictions may apply. https://doi.org/10.1021/acsanm.8b00798.

The content of this document may vary from the final published version.

(16) Xiong, D.; Zhang, Q.; Li, W.; Li, J.; Fu, X.; Cerqueira, M. F.; Alpuim, P.; Liu, L. AtomicLayer-Deposited Ultrafine $\mathrm{MoS}_{2}$ Nanocrystals on Cobalt Foam for Efficient and Stable Electrochemical Oxygen Evolution. Nanoscale 2017, 9 (8), 2711-2717.

(17) Proffen, T.; Billinge, S. J. L.; Egami, T.; Louca, D. Structural Analysis of Complex Materials Using the Atomic Pair Distribution Function - a Practical Guide. Zeitschrift für Krist. Cryst. Mater. 2003, 218 (2), 132.

(18) Billinge, S. J. L.; Kanatzidis, M. G. Beyond Crystallography: The Study of Disorder, Nanocrystallinity and Crystallographically Challenged Materials with Pair Distribution Functions. Chem. Commun. 2004, No. 7, 749.

(19) Petkov, V. Nanostructure by High-Energy X-Ray Diffraction. Mater. Today 2oo8, 11 (11), 28-38.

(20) Elam, J. W.; Groner, M. D.; George, S. M. Viscous Flow Reactor with Quartz Crystal Microbalance for Thin Film Growth by Atomic Layer Deposition. Rev. Sci. Instrum. 2002, 73 (8), 2981-2987.

(21) Kropf, A. J.; Katsoudas, J.; Chattopadhyay, S.; Shibata, T.; Lang, E. A.; Zyryanov, V. N.; Ravel, B.; McIvor, K.; Kemner, K. M.; Scheckel, K. G.; et al. The New MRCAT (Sector 10) Bending Magnet Beamline at the Advanced Photon Source. In AIP Conference Proceedings; 2010; Vol. 1234, pp 299-302.

(22) Calvin, S. XAFS for Everyone; CRC/Taylor \& Francis: Boca Raton, FL, 2013.

(23) Ravel, B.; Newville, M. ATHENA , ARTEMIS , HEPHAESTUS : Data Analysis for X-Ray Absorption Spectroscopy Using IFEFFIT. J. Synchrotron Radiat. 2005, 12 (4), 537-541.

(24) Toby, B. H.; Von Dreele, R. B. GSAS-II : The Genesis of a Modern Open-Source All Purpose Crystallography Software Package. J. Appl. Crystallogr. 2013, 46 (2), 544-549.

(25) Aoun, B. Fullrmc, a Rigid Body Reverse Monte Carlo Modeling Package Enabled with Machine Learning and Artificial Intelligence. J. Comput. Chem. 2016, 37 (12), 1102-1111.

(26) Le Roux, S.; Petkov, V. ISAACS - Interactive Structure Analysis of Amorphous and Crystalline Systems. J. Appl. Crystallogr. 2010, 43 (1), 181-185.

(27) Mane, A. U.; Letourneau, S.; Mandia, D. J.; Liu, J.; Libera, J. A.; Lei, Y.; Peng, Q.; Graugnard, E.; Elam, J. W. Atomic Layer Deposition of Molybdenum Disulfide Films Using $\mathrm{MoF}_{6}$ and $\mathrm{H}_{2}$ S. J. Vac. Sci. Technol. A Vacuum, Surfaces, Film. 2018, 36 (1), 01A125.

(28) Seghete, D.; Rayner, G. B.; Cavanagh, A. S.; Anderson, V. R.; George, S. M. Molybdenum Atomic Layer Deposition Using $\mathrm{MoF}_{6}$ and $\mathrm{Si}_{2} \mathrm{H}_{6}$ as the Reactants. Chem. Mater. 2011, 23 (7), 1668-1678.

(29) Joensen, P.; Frindt, R. F.; Morrison, S. R. Single-Layer MoS 2 . Mater. Res. Bull. 1986, 21 (4), 457-461.

(30) Ressler, T. Bulk Structural Investigation of the Reduction of $\mathrm{MoO}_{3}$ with Propene and the Oxidation of $\mathrm{MoO}_{2}$ with Oxygen. J. Catal. 2002, 210 (1), 67-83.

(31) Lassalle-Kaiser, B.; Merki, D.; Vrubel, H.; Gul, S.; Yachandra, V. K.; Hu, X.; Yano, J. Evidence from in Situ X-Ray Absorption Spectroscopy for the Involvement of Terminal Disulfide in the Reduction of Protons by an Amorphous Molybdenum Sulfide Electrocatalyst. J. Am. Chem. Soc. 2015, 137 (1), 314-321. 
This is an author-produced, peer-reviewed version of this article. The final, definitive version of this document can be found online at $A C S$ Applied Nano Materials, published by American Chemical Society. Copyright restrictions may apply. https://doi.org/10.1021/acsanm.8b00798.

The content of this document may vary from the final published version.

(32) Rehr, J. J.; Kas, J. J.; Vila, F. D.; Prange, M. P.; Jorissen, K. Parameter-Free Calculations of X-Ray Spectra with FEFF9. Phys. Chem. Chem. Phys. 2010, 12 (21), 5503.

(33) Bronsema, K. D.; De Boer, J. L.; Jellinek, F. On the Structure of Molybdenum Diselenide and Disulfide. Zeitschrift für Anorg. und Allg. Chemie 1986, 540 (9-10), 15-17.

(34) Eda, G.; Yamaguchi, H.; Voiry, D.; Fujita, T.; Chen, M.; Chhowalla, M. Photoluminescence from Chemically Exfoliated $\mathrm{MoS}_{2}$. Nano Lett. 2011, 11 (12), 5111-5116.

(35) Zubavichus, Y. V.; Golub, A. S.; Novikov, Y. N.; Slovokhotov, Y. L.; Nesmeyanov, A. N.; Schilling, P. J.; Tittsworth, R. C. XAFS Study of $\mathrm{MoS}_{2}$ Intercalation Compounds. Le J. Phys. IV 1997, 7 (C2), C2-1057-C2-1059.

(36) Mignuzzi, S.; Pollard, A. J.; Bonini, N.; Brennan, B.; Gilmore, I. S.; Pimenta, M. A.; Richards, D.; Roy, D. Effect of Disorder on Raman Scattering of Single-Layer $\mathrm{MoS}_{2}$. Phys. Rev. B 2015, 91 (19), 195411.

(37) Addou, R.; McDonnell, S.; Barrera, D.; Guo, Z.; Azcatl, A.; Wang, J.; Zhu, H.; Hinkle, C. L.; Quevedo-Lopez, M.; Alshareef, H. N.; Colombo, L.; Hsu, J. W. P.; Wallace, R. M., Impurities and Electronic Property Variations of Natural $\mathrm{MoS}_{2}$ Crystal Surfaces. ACS Nano 2015, 9 (9), 9124-9133.

(38) Pierucci, D.; Henck, H.; Ben Aziza, Z.; Naylor, C. H.; Balan, A.; Rault, J. E.; Silly, M. G.; Dappe, Y. J.; Bertran, F.; Le Fèvre, P.; Sirotti, F.; Johnson, A. T. C.; Ouerghi, A., Tunable Doping in Hydrogenated Single Layered Molybdenum Disulfide. ACS Nano 2017, 11 (2), 1755-1761.

(39) Cramer, S. P.; Liang, K. S.; Jacobson, A. J.; Chang, C. H.; Chianelli, R. R. EXAFS Studies of Amorphous Molybdenum and Tungsten Trisulfides and Triselenides. Inorg. Chem. 1984, 23 (9), 1215-1221.

(40) Weber, T.; Muijsers, J. C.; Niemantsverdriet, J. W. Structure of Amorphous $\mathrm{MoS}_{3}$. J. Phys. Chem. 1995, 99 (22), 9194-9200.

(41) Buzaneva, E.; Vdovenkova, T.; Gorchinsky, A.; Senkevich, A.; Nemoshkalenko, V.; Klein, A.; Tomm, Y. XPS and STS of Layered Semiconductor MoSx. J. Electron Spectros. Relat. Phenomena 1994, 68 (C), 763-769.

(42) Liang, K. S.; DeNaufville, J. P.; Jacobson, A. J.; Chianelli, R. R.; Betts, F. Structure of Amorphous Transition Metal Sulfides. J. Non. Cryst. Solids 1980, 35-36, 1249-1254.

(43) Rettig, S. J.; Trotter, J. Refinement of the Structure of Orthorhombic Sulfur, a-S8. Acta Crystallogr. Sect. C Cryst. Struct. Commun. 1987, 43 (12), 2260-2262. 


\section{TOC FIGURE}

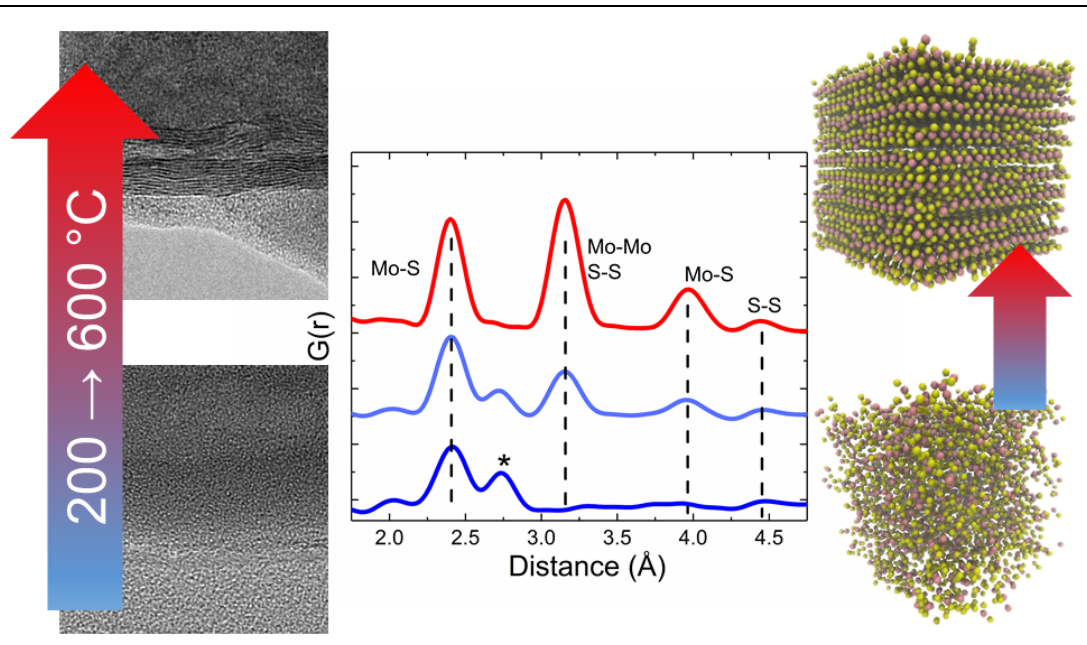

Keywords: molybdenum disulfide; $\mathrm{MoS}_{2}$; atomic layer deposition; ALD; X-ray absorption spectroscopy; XAS; high energy X-ray diffraction; XAS; fullrmc; reverse Monte Carlo; 